\title{
Overexpression of the receptor for hyaluronan-mediated motility, correlates with expression of microtubule-associated protein in human oral squamous cell carcinomas
}

\author{
HIDEO SHIGEISHI, SHINICHI FUJIMOTO, MISATO HIRAOKA, SHIGEHIRO ONO, \\ MASAYUKI TAKI, KOUJI OHTA, KOICHIRO HIGASHIKAWA and NOBUYUKI KAMATA \\ Department of Oral and Maxillofacial Surgery, Division of Cervico-Gnathostomatology, Graduate School of \\ Biomedical Sciences, Hiroshima University, 1-2-3 Kasumi, Minami-ku, Hiroshima 734-8553, Japan
}

Received December 31, 2008; Accepted March 4, 2009

DOI: 10.3892/ijo_00000286

\begin{abstract}
Receptor for hyaluronan-mediated motility (RHAMM) has previously been characterized as a cell surface receptor for hyaluronan and a microtubuleassociated intracellular hyaluronan binding protein. We examined the expression of RHAMM mRNA in 43 oral squamous cell carcinomas (SCCs) and 7 normal gingivae by real-time RT-PCR. The expression level of RHAMM mRNA was significantly higher in oral SCCs than normal gingivae $(\mathrm{P}=0.0047)$. Forty out of 43 oral SCCs showed expression of RHAMM splice variant (48 bp deletion). We immunohistochemically confirmed the protein expression of RHAMM in oral SCCs with higher levels of RHAMM mRNA. Patients with oral SCC who had high RHAMM expression had shorter survival rates than patients with low expression. However, it was not statistically significant. It has been reported that RHAMM interacts with spindle assembly factors such as microtubule-associated protein (TPX2). To investigate the expression of microtubuleassociated protein in oral SCCs, mRNA expression of TPX2 was also examined by real-time RT-PCR. The expression level of TPX2 mRNA was significantly higher in oral SCCs than normal gingivae $(\mathrm{P}=0.046)$. Furthermore, a significant correlation between the mRNA expression levels of TPX2 and RHAMM was recognized $(\mathrm{P}=0.011)$. The results indicate that there is a strong correlation between the mRNA expression levels of TPX2 and RHAMM in oral SCCs. Our observations suggest that the up-regulations of human RHAMM and TPX2 gene correlate with the malignant condition and might be linked to the increased or abnormal cell proliferation in human oral SCCs.
\end{abstract}

Correspondence to: Dr Hideo Shigeishi, Department of Oral and Maxillofacial Surgery, Division of Cervico-Gnathostomatology, Graduate School of Biomedical Sciences, Hiroshima University, 1-2-3 Kasumi, Minami-ku, Hiroshima 734-8553, Japan

E-mail: shige@hiroshima-u.ac.jp

Key words: receptor for hyaluronan-mediated motility, microtubuleassociated protein, oral squamous cell carcinomas

\section{Introduction}

The receptor for hyaluronan-mediated motility (RHAMM) has been identified as a cell surface receptor for hyaluronan and microtubule-associated protein which interacts with the actin cytoskeleton $(1,2)$. RHAMM localizes to the centrosome maintaining the spindle integrity through direct interaction with microtubules (3). The amino terminus of RHAMM directly interacts with microtubules, while the carboxyterminus is essential for centrosomal localization (2-4). RHAMM interacts with spindle assembly factors such as microtubule-associated protein (TPX2) (4). TPX2 is a microtubule-associated protein and is required for microtubule formation at kinetochores in mammalian cells (5). TPX2 initiates spindle assembly by bundling the microtubules and by activating Aurora A kinase in a microtubule-dependent manner (6). Aurora A kinase accumulates at centrosomes from $\mathrm{S}$ phase to the end of mitosis and has been implicated in centrosome maturation and spindle assembly (7). Expression of Aurora A is associated with genetic instability and poor prognosis in human cancers (8). RHAMM is also involved in regulating extracellular-regulated kinase (ERK) (9). RHAMM can bind ERK kinase and control the expression of ERK. ERK is activated by upstream kinase Raf and MEK and play a role in cell defferentiation and proliferation (10).

RHAMM colocalizes with TPX2 during mitosis in myeloma cells (4). The carboxy-terminal leucine zipper of RHAMM is required for its spindle pole localization and this domain mediates the interaction of TPX2 (11). Furthermore, overexpression of RHAMM has been associated with centrosomal abnormalities in myeloma cells (4). These observations suggest that RHAMM and TPX2 are structural components of the spindle and contribute to maintaining spindle integrity during mitosis.

Previously, overexpression of RHAMM has been reported in different tumor types including multiple myeloma, breast cancer, endometrial cancer and colorectal cancer (12-16). Expression of RHAMM induces tumor proliferative activities and correlates with poor prognosis in multiple myeloma (17). These observations suggest that expression of RHAMM correlates with tumor progression in several types of human cancers. Human RHAMM cDNA was cloned and contained 725 amino acids that encoded an $85 \mathrm{kDa}$ protein (18). Three 
distinct RHAMM gene products, full-length RHAMM, splice variant of $48 \mathrm{bp}$ deletion $\left(\mathrm{RHAMM}^{-48}\right)$ and variant of $147 \mathrm{bp}$ deletion $\left(\right.$ RHAMM $\left.^{-147}\right)$, were cloned from multiple myeloma cells (12). All of the detected RHAMM splice variants contain exon 4, which is alternatively spliced in murine RHAMM (12). Deletion of RHAMM exon 4 disrupts interaction with microtubules at the amino-terminus (4). RHAMM exon 4 plays a significant role in microtubule interaction during mitosis. Deletion of RHAMM ${ }^{-48}$ and RHAMM $^{-147}$ lie outside of hyaluronan-binding domains (4). Although the importance of these deletion variants is not apparent, the deletion variants might encode conformationally altered RHAMM and different localization from that of fulllength RHAMM.

In human carcinomas, RHAMM participates in tumor progression and metastasis. In the present study, we examined the expression of the human RHAMM gene in oral squamous cell carcinomas to clarify the correlation between RHAMM expression and clinicopathological factors. Expression of RHAMM splice variants (RHAMM ${ }^{-48}$ and RHAMM $^{-147}$ ) were also examined. Furthermore, to clarify the correlation between RHAMM and TPX2 in oral SCCs, mRNA expression levels of TPX2 were examined.

\section{Materials and methods}

Tissue samples. We examined 43 oral squamous cell carcinomas (SCCs) and seven normal gingivae. Tumor tissues and specimens of normal gingivae were obtained with informed consent and approval from the Institutional Review Board at Hiroshima University Dental Hospital (Japan) between 1995 and 2007. The oral SCC samples were derived from the tongue, upper gingiva, lower gingiva and buccal mucosa. The clinical staging was determined according to the International Union Against Cancer TNM classification (19). The primary tumors were classified histopathologically as well- or moderately-differentiated in the World Health Organization (WHO) classification (20). For molecular analyses, tissue samples obtained at the time of surgery were frozen immediately in liquid nitrogen and stored at $-80^{\circ} \mathrm{C}$.

RNA extraction and quantitative RT-PCR analysis. RNA was extracted with an RNAeasy mini kit (Qiagen, Hilden, Germany). One microgram of total RNA was subjected to a reverse-transcriptase reaction using the first-strand cDNA synthesis kit (Amersham Biosciences, Uppsala, Sweden). mRNA levels were quantified using a real-time fluorescence detection method (21). Fluorescence was detected using the laser detector of the fluorescent quantitative detection system (LineGene FQD-33A, Bio Flux, Tokyo, Japan) and detection was carried out by measuring the binding of a fluorescent dye, SYBR-Green I, to double-stranded DNA. PCR was run in microtubes at a volume of $20 \mu \mathrm{l}$. The reaction mixture contained $1.0 \mu \mathrm{g}$ of cDNA, $10 \mu \mathrm{l}$ of SYBR-Green PCR master mix (Toyobo, Tokyo, Japan) and 10 pmol of each pair of oligonucleotide primers. Previously published primer sequences were used for RHAMM and TPX2 $(12,22)$. The primer sequences were: RHAMM; 5'-CAGGTCACCCAAA GGAGTCTCG-3' (sense), 5'-CAAGCTCATCCAGTGTT
TGC-3' (antisense) (537 bp PCR products), TPX2; 5'-ACCT TGCCCTACTAAGATT-3' (sense), 5'-AATGTGGCACAG GTTGAGC-3' (antisense) (176 bp PCR products), and G3PDH; 5'-ACCACAGTCCATGCCATCAC-3' (sense), 5'-TCCACCACCCTGTGGCTGTA-3' (antisense). The PCR program was as follows: initial melting at $95^{\circ} \mathrm{C}$ for $30 \mathrm{sec}$ followed by 40 cycles at $95^{\circ} \mathrm{C}$ for $15 \mathrm{sec}, 57^{\circ} \mathrm{C}$ for $10 \mathrm{sec}$ and $72^{\circ} \mathrm{C}$ for $15 \mathrm{sec}$. To confirm amplification specificity, the PCR products were subjected to subsequent agarose gel electrophoresis. The threshold cycle (CT) of each PCR product was defined as the cycle number at which the fluorescence signal passed the fixed threshold. Duplicate samples for each case were examined. The $2^{-\Delta c t}$ method is a convenient way to analyze the relative changes in gene expression from real-time PCR experiments, as described previously (23). The average CT was calculated for both RHAMM/TPX2 and G3PDH and $\triangle \mathrm{CT}$ (Average $\mathrm{CT}_{\text {RHAMM }}$ - Average $\mathrm{CT}_{\mathrm{G} 3 \mathrm{PDH}}$ ) was determined. The relative quantification of RHAMM/TPX2 mRNA was calculated as $2^{-\Delta c t}(23)$.

Detection of splice variants of RHAMM and sequencing analysis. One microgram of total RNA was subjected to a reverse-transcriptase reaction using the first-strand cDNA synthesis kit (Amersham Biosciences). To detect two splice variants, RHAMM-48 (48 bp deletion) and RHAMM $^{-147}$ (147 bp deletion), we used the primer sets as described previously (12). We first examined the expression of two splice variants in several oral cancer cell lines. We could detect RHAMM $^{-48}$ splice variant in HSC3 cell lines. HSC3 cell lines were used as a positive control for the detection of RHAMM $^{-48}$. We could not detect RHAMM ${ }^{-48}$ splice variant in HO-1-u-1 cell lines. HO-1-u-1 cell lines were used as a negative control. The primer sequences for RHAMM-48 were: 5'-GGCCGTCAACATGTCCTTTCCTA-3' (sense) and 5'-TTGGGCTATTTTCCCTTGAGACTC-3' (antisense); RHAMM-147, 5'-AGGAGGAACAAGCTGAAAGG-3' (sense) and 5'-TTCCTGAGCTGCACCATGTT-3' (antisense). The target sequence was amplified in a $50 \mu 1$ reaction volume containing $1 \mu \mathrm{g}$ cDNA, $0.2 \mathrm{mM}$ dNTPs, $1.5 \mathrm{mM}$ $\mathrm{MgCl}_{2}, 0.2 \mu \mathrm{M}$ each primer and $1.0 \mathrm{U}$ Platinum Taq (Invitrogen, San Diego, CA). PCR amplification consisted of 35 cycles $\left(94^{\circ} \mathrm{C}\right.$ for $1 \mathrm{~min}, 57^{\circ} \mathrm{C}$ for $30 \mathrm{sec}$ and $72^{\circ} \mathrm{C}$ for $2 \mathrm{~min}$ ) after the initial Taq Gold activation step $\left(94^{\circ} \mathrm{C}\right.$ for $\left.7 \mathrm{~min}\right)$. After the PCR was completed, $10 \mu 1$ of PCR product were analyzed by electrophoresis using $2 \%$ agarose gels. For the sequencing reaction, the BigDye Terminator $\mathrm{v} 1.1$ cycle sequencing kit (Perkin-Elmer ABI, Foster City, CA) was used. Amplified DNA fragments were sequenced by ABI PRISM 310 genetic analyzer (Perkin-Elmer ABI).

Immunohistochemistry. Immunohistochemical staining was performed by the immunoperoxidase technique following antigen retrieval with microwave treatment $(500 \mathrm{~W}, 10 \mathrm{~min})$ in citrate buffer $\mathrm{pH}$ 6.0. After peroxidase block by $3 \% \mathrm{H}_{2} \mathrm{O}_{2}$ methanol for $10 \mathrm{~min}$, specimens were blocked with PBS containing 5\% normal horse serum (Vector Laboratories, Inc., Burlingame, CA). For the staining of RHAMM, anti-RHAMM monoclonal antibody (Sanbio B.V, The Netherlands) (diluted 1:100) was used. After $6 \mathrm{~h}$ incubation at room temperature with primary antibody, specimens were rinsed briefly with 

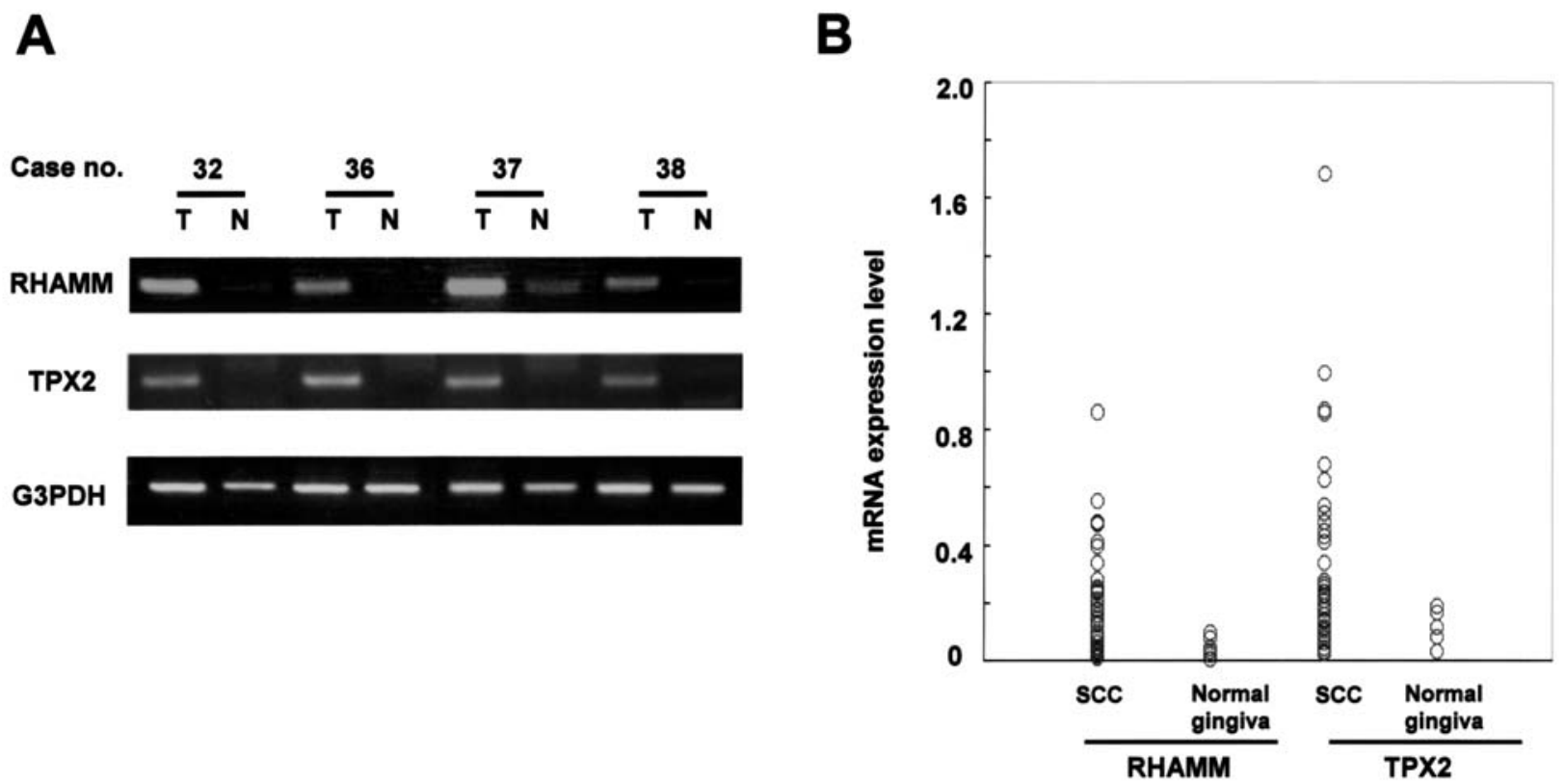

Figure 1. (A) mRNA expression of RHAMM and TPX2 in oral SCCs and normal gingivae by RT-PCR analysis. Tumor tissues (T) and corresponding normal gingivae $(\mathrm{N})$ from the same patients. The expression of G3PDH was used as a positive control. (B) Levels of RHAMM and TPX2 mRNA expression in oral SCCs and normal gingivae by quantitative RT-PCR analysis. Each point represents the RHAMM or TPX2 mRNA expression level. RHAMM mRNA expression levels were significantly higher in oral SCCs than normal gingivae (Mann-Whitney U test, $\mathrm{P}=0.0047$ ). TPX2 mRNA expression levels were also significantly higher in oral SCCs than normal gingivae (Mann-Whitney U test, $\mathrm{P}=0.046$ ).

PBS and incubated with secondary antibody (anti-mouse IgG antibody, Medical and Biological Laboratories, Tokyo, Japan) (diluted 1:100) for $1 \mathrm{~h}$ at room temperature. Specimens were rinsed with PBS and incubated with DAB (Dako, Tokyo, Japan). RHAMM staining was graded as positive (at least $10 \%$ of tumor cells showed moderate to intense immunoreactivity) or negative $(<10 \%$ of tumor cells showed weak or no immunoreactivity). According to this grading protocol, we examined all sections of the immunostained specimens randomly to make the grading as objective as possible (one slide was examined by at least two people). We counted at least 1000 tumor cells or normal gingival epithelial cells per one slide.

Statistical methods. The results of quantitative RT-PCR analysis were compared with the patient's clinicopathological information using the Mann-Whitney U test, Kruskal-Wallis test and Spearman's correlation coefficient by rank test. The overall survival rates were calculated by the Kaplan-Meier method and analyzed by means of the log-rank test. P-values $<0.05$ were regarded as statistically significant.

\section{Results}

Expression of RHAMM mRNA in oral SCCs and normal gingivae. We examined the expression of RHAMM mRNA in 43 oral SCCs and 7 normal gingivae by real-time RT-PCR. The mean expression level of RHAMM mRNA was higher in oral SCCs $(0.20 \pm 0.16)$ than normal gingivae $(0.0391 \pm 0.035)$ as shown in Fig. 1A and B. The expression level of RHAMM mRNA was significantly higher in oral SCCs than normal gingivae (Mann-Whitney U test, $\mathrm{P}=0.0047$ ). Data on RHAMM mRNA expression, tumor size, clinical stage and lymph node metastasis are summarized in Table I. The expression of RHAMM mRNA was not correlated to clinicopathological factors such as histology, tumor size and lymph node metastasis.

Correlation of mRNA expression levels between TPX2 and RHAMM. We also examined the expression of TPX 2 mRNA in 43 oral SCCs and 7 normal gingivae by real-time RT-PCR. As shown in Fig. 1B, mRNA expression levels of TPX2 were significantly higher in oral SCCs $(0.33 \pm 0.32)$ than normal gingivae $(0.12 \pm 0.063)$ (Mann-Whitney $U$ test, $\mathrm{P}=0.046)$. Data on TPX 2 mRNA expression, tumor size, clinical stage and lymph node metastasis are summarized in Table I. TPX2 mRNA was significantly higher in stage III/IV oral SCCs than in stage I/II oral SCCs (Mann-Whitney U test, $\mathrm{P}=0.010)$. Next, the co-expression of TPX2 and RHAMM were examined. A significant correlation was found between the mRNA expression levels of RHAMM and TPX2 (Spearman's correlation coefficient by rank test, $\mathrm{P}=0.011$ ) (Fig. 2).

Expression of RHAMM splice variants in oral SCCs. Expression of two splice variants, RHAMM $^{-48}$ and RHAMM $^{-147}$, were examined in 43 oral SCCs and 7 normal gingivae. RHAMM $^{-48}$ was identified in oral SCC cell lines HO-1-u-1 using PCR analysis, which amplifies two products (Fig. 3B). RHAMM $^{-48}$ could not be identified in oral SCC cell lines HSC3 using PCR analysis. HO-1-u-1 and HSC3 cell lines were used as a control for the detection of RHAMM splice variants. We confirmed PCR products of $613 \mathrm{bp}$ corresponding to RHAMM and $565 \mathrm{bp}$ corresponding to $48 \mathrm{bp}$ deletion of RHAMM by sequencing analysis. Forty-eight bp deletion of RHAMM was detected by sequencing of 565 bp PCR products (Fig. 3C). 
Table I. Expression of RHAMM and TPX2 mRNA in oral SCCs and its correlation with clinicopathological parameters.

\begin{tabular}{|c|c|c|c|c|c|}
\hline & \multirow[b]{2}{*}{ No. of cases } & \multicolumn{2}{|c|}{ Expression level of RHAMM ${ }^{b}$} & \multicolumn{2}{|c|}{ Expression level of TPX $2^{\mathrm{b}}$} \\
\hline & & Mean $\pm \mathrm{SD}$ & P-value ${ }^{c}$ & Mean \pm SD & P-value \\
\hline \multicolumn{6}{|l|}{ Histology ${ }^{a}$} \\
\hline Well & 18 & $0.20 \pm 0.19$ & 0.98 & $0.27 \pm 0.22$ & 0.20 \\
\hline Moderate & 25 & $0.19 \pm 0.19$ & & $0.43 \pm 0.41$ & \\
\hline \multicolumn{6}{|l|}{ Tumor size ${ }^{\mathrm{a}}$} \\
\hline $\mathrm{T} 1$ & 5 & $0.22 \pm 0.27$ & 0.16 & $0.44 \pm 0.70$ & 0.37 \\
\hline $\mathrm{T} 2$ & 20 & $0.20 \pm 0.15$ & & $0.27 \pm 0.23$ & \\
\hline $\mathrm{T} 3$ & 7 & $0.20 \pm 0.29$ & & $0.39 \pm 0.29$ & \\
\hline $\mathrm{T} 4$ & 11 & $0.19 \pm 0.15$ & & $0.36 \pm 0.23$ & \\
\hline \multicolumn{6}{|c|}{ Clinical stage $^{\mathrm{a}}$} \\
\hline $\mathrm{I}+\mathrm{II}$ & 22 & $0.21 \pm 0.17$ & 0.63 & $0.28 \pm 0.37$ & 0.010 \\
\hline III + IV & 21 & $0.19 \pm 0.20$ & & $0.39 \pm 0.24$ & \\
\hline \multicolumn{6}{|c|}{ Lymph node metastasis } \\
\hline Positive & 11 & $0.17 \pm 0.15$ & 0.66 & $0.40 \pm 0.28$ & 0.19 \\
\hline Negative & 32 & $0.21 \pm 0.20$ & & $0.31 \pm 0.33$ & \\
\hline
\end{tabular}

${ }^{a}$ According to the American Joint Committee on Cancer Staging Manual, 5th edition. ${ }^{\text {b } m R N A ~ l e v e l s ~ w e r e ~ q u a n t i f i e d ~ u s i n g ~ a ~ r e a l-t i m e ~ R T-P C R ~}$ method. 'P-value, the correlation was analyzed using the Mann-Whitney U test or Kruskal-Wallis test and P-values are shown. P-values $<0.05$ were regarded as statistically significant. Expression of TPX2 mRNA was significantly higher in stage III/IV oral SCCs than in stage I/II oral SCCs (Mann-Whitney U test, $\mathrm{P}=0.010$ ).

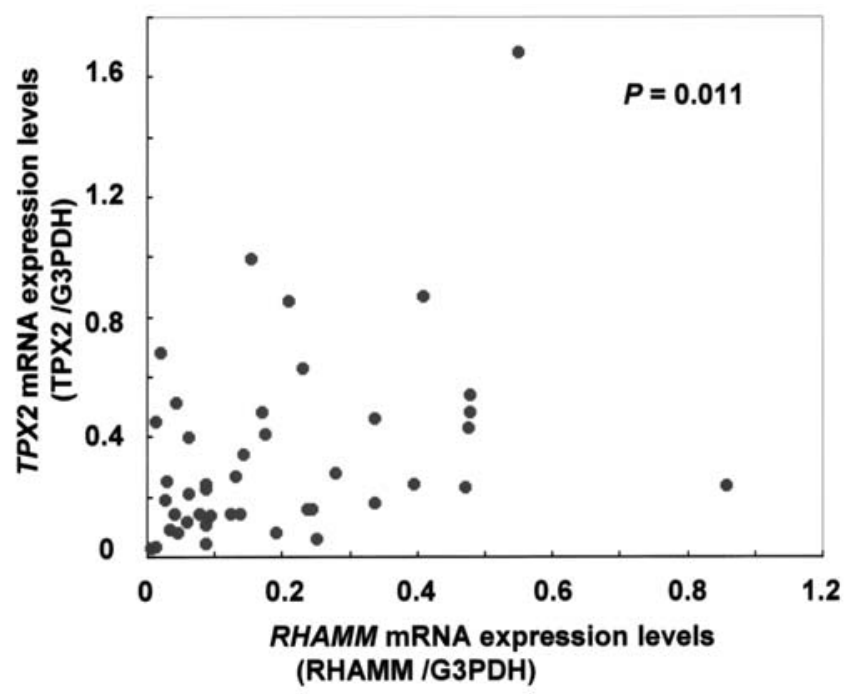

Figure 2. Correlation between mRNA expression levels of RHAMM and TPX2 (Spearman's correlation coefficient by rank test, $\mathrm{P}=0.011$ ).

Forty out of 43 oral SCCs showed expression of RHAMM-48 splice variants (Fig. 4A). We could not detect expression of RHAMM $^{-48}$ in the other 3 oral SCCs. Two (N4 and N6) out of 7 normal cases showed expression of RHAMM-48 (Fig. 4A). We could not detect expression of RHAMM $^{-48}$ in the other 5 normal cases (Fig. 4A). On the other hand, expression of RHAMM $^{-147}$ could not be detected in any of the 43 oral SCCs and 7 normal gingivae (Fig. 4B).
Immunohistochemistry for RHAMM in oral SCCs. We next studied the expression of RHAMM protein immunohistochemically in 13 oral SCCs with higher levels of RHAMM mRNA (expression level $>0.1$ ). Normal gingiva showed weak or no immunostaining (Fig. 5A). Twelve out of 13 oral SCCs with higher levels of RHAMM mRNA showed positive staining. RHAMM expression was observed in the cytoplasm of the cancer cells (Fig. 5B).

Correlation between mRNA expression levels of RHAMM and survival rates of oral SCC patient. A total of 35 oral SCC cases were investigated for survival rates. The 14 cases whose tumors expressed increased levels of RHAMM mRNA (expression level $>0.1$ ) showed a worse survival rate than the 21 cases expressing RHAMM mRNA at lower levels (expression level <0.1). However, a significant difference was not found (log-rank test, $\mathrm{P}>0.05$ ) (Fig. 6).

\section{Discussion}

RHAMM has previously been characterized as a cell surface receptor for hyaluronan and a microtubule-associated intracellular hyaluronan binding protein $(1,2)$. RHAMM mRNA expression has been identified in normal human tissues including colon, stomach, ovary and testis (24). Overexpression of RHAMM has also been reported in several human cancers (13-16). In the present study, we investigated the expression of RHAMM mRNA in oral SCCs. The expression of RHAMM mRNA was significantly higher in 
A

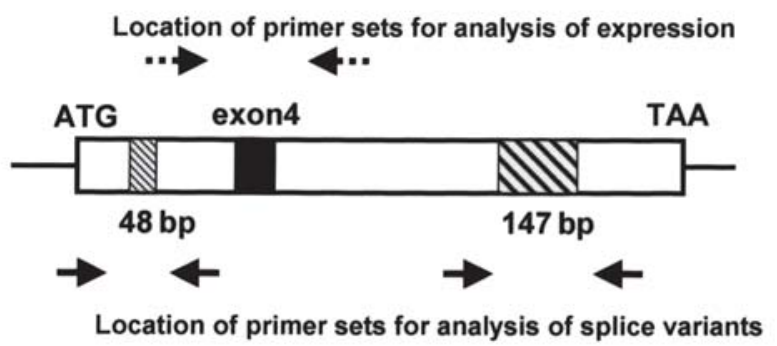

C

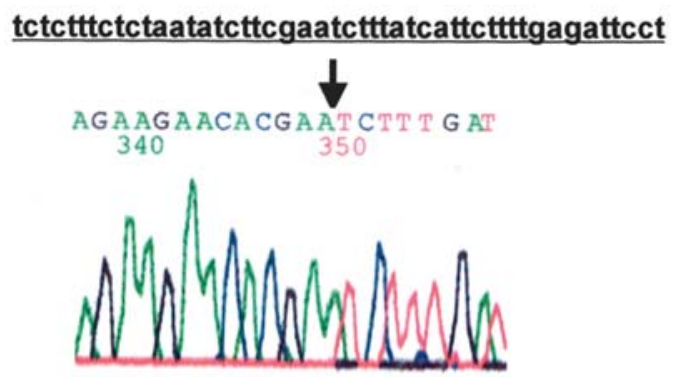

B

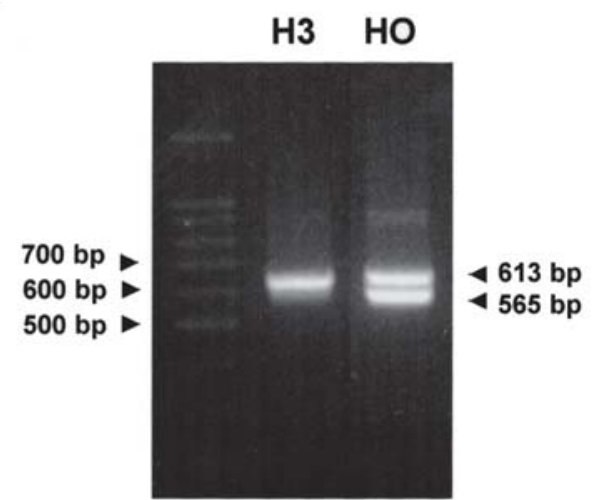

Figure 3. Expression of splice variants of RHAMM in oral SCC cell lines. (A) Location of RHAMM splice variants (RHAMM ${ }^{-48}$ and RHAMM $^{-147}$ ) and PCR primers are shown. (B) Expression of RHAMM ${ }^{-48}$ was identified in HO-1-u-1 oral SCC cell lines using PCR analysis. H3, HSC3 cell; HO, HO-1-u-1 cell. (C) Sequencing analysis of 565 bp PCR products corresponding to 48 bp deletion using RHAMM ${ }^{-48}$ antisense primer.

A

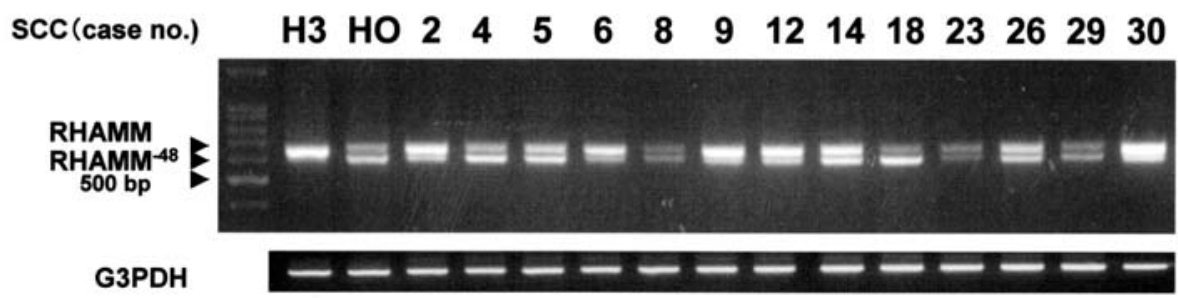

Normal gingiva (case no.)

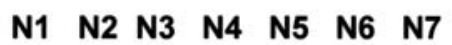

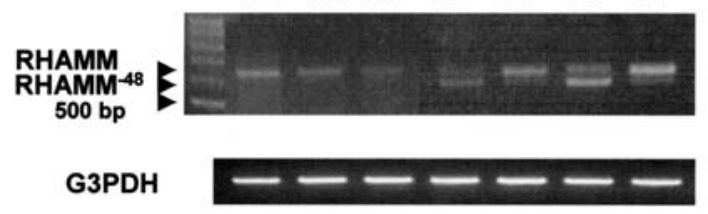

B
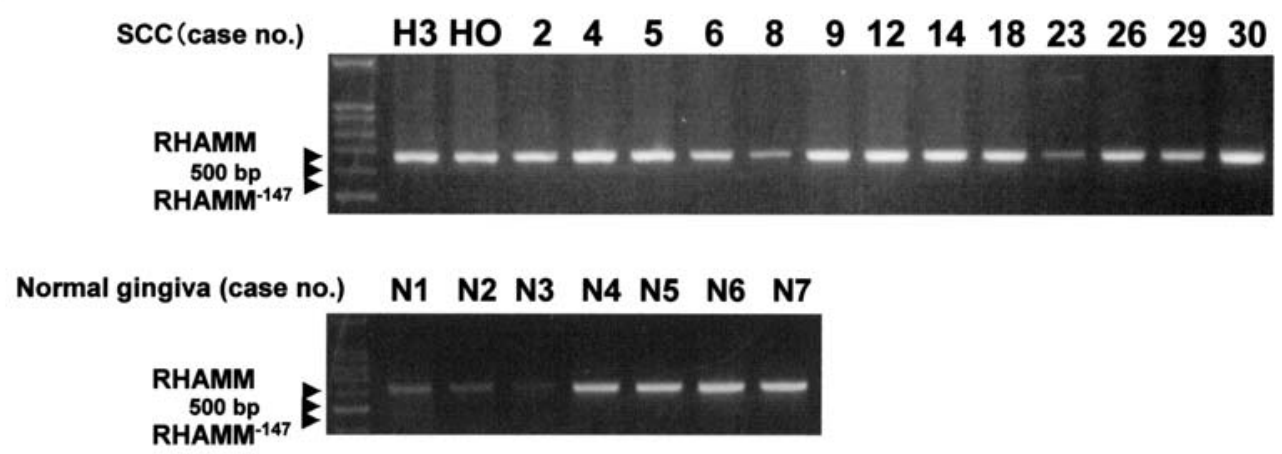

Figure 4. Expression of splice variants of RHAMM in oral SCCs and normal gingiva. (A) Expression of RHAMM ${ }^{-48}$ was identified in oral SCCs and normal gingiva using PCR analysis. H3, HSC3 cell; HO, HO-1-u-1 cell. G3PDH was used as a positive control. (B) Expression of RHAMM-147 was not identified in oral SCCs and normal gingiva using PCR analysis. 

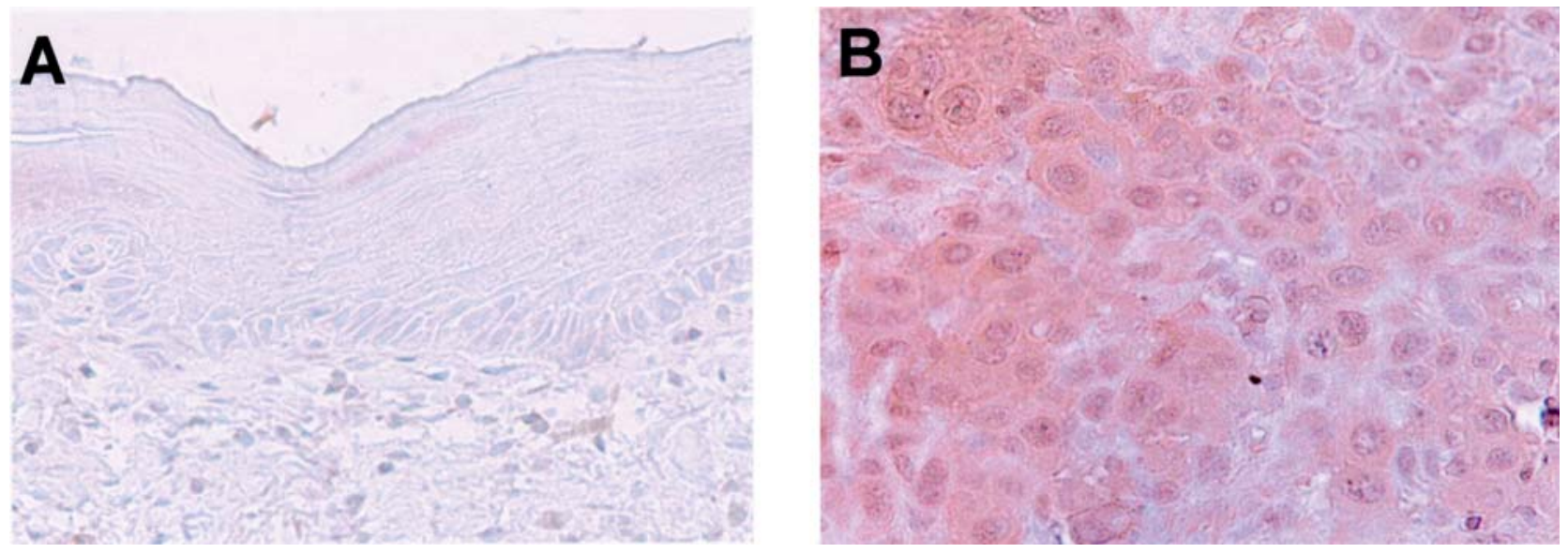

Figure 5. Immunohistochemistry for RHAMM in oral SCC. (A) Normal gingiva shows weak or no immunostaining of RHAMM expression. (B) RHAMM expression is observed in the cytoplasm of the cancer cells.

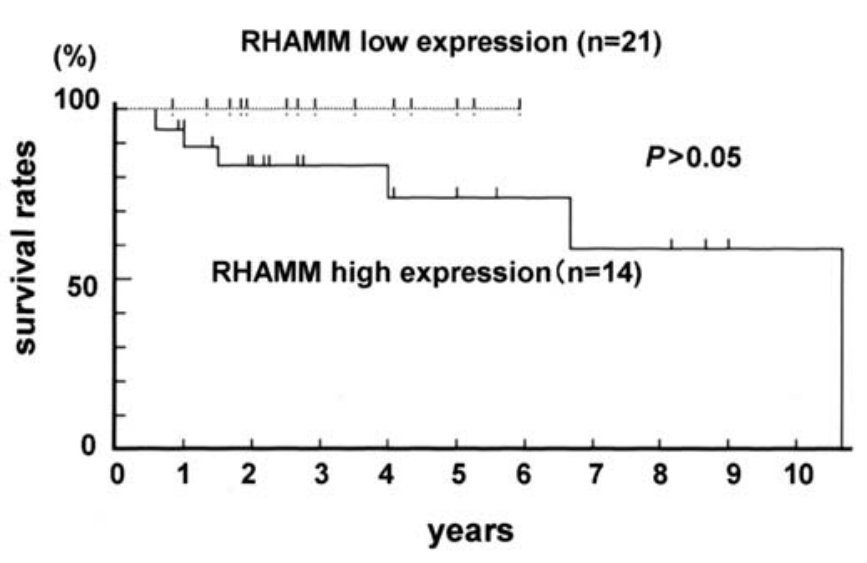

Figure 6. Correlation between mRNA expression levels of RHAMM and survival rates of OSCC patients. The overall survival rates were calculated by the Kaplan-Meier method and analyzed by means of the log-rank test. Significant correlation was not observed $(\mathrm{P}>0.05)$.

oral SCCs than normal gingivae. RHAMM protein expression was observed in oral SCCs with higher levels of RHAMM mRNA. On the other hand, normal gingiva showed weak or no immunostaining. We examined the correlation between the expression of RHAMM mRNA and different clinical characteristics, including tumor size, clinical stage and lymph node metastasis. Previous studies showed a correlation between RHAMM expression and clinicopathological factors in human cancers (14-17). RHAMM expression was associated with tumor progression in epithelial tumors such as breast and endometrial cancers $(13,14)$. Although we could not find a significant correlation between expression of RHAMM expression levels and clinical characteristics, patients with tumors that have low expression of RHAMM mRNA have longer survival rate than patients with high expression.

Two splice variants of RHAMM have been described in malignant cells in multiple myeloma patients (12). RHAMM-48 and RHAMM $^{-147}$ splice variants were overexpressed in multiple myeloma cells and all of the RHAMM variants contain exon 4, which is alternatively spliced in murine RHAMM (12). High expression of RHAMM ${ }^{-48}$ splice variant was correlated with poor survival of myeloma patients (17). We detected expression of RHAMM $^{-48}$ splice variant in 40 out of 43 oral SCCs. In contrast, 2 of the 7 normal gingivae showed expression of RHAMM-48. Our results suggested that increased expression of RHAMM and high incidence of RHAMM splicing might contribute to the biological response such as tumor proliferation in oral SCC.

Previously, Maxwell et al reported that RHAMM interacted with the spindle assembly factors such as dynein and TPX2 (4). The spindle assembly factors ensure fidelity of chromosome segregation by delaying the cell cycle until all chromosomes are correctly attached to the spindle. TPX2 is a cell cycle-associated protein and plays a significant role in the microtubule formation at kinetochores (5), although its overexpression induces monopolar spindle structures in Xenopus egg extracts (25). Overexpression of TPX2 has been reported in several human cancers (22). In the present study, we found that the expression level of TPX2 mRNA was significantly increased in oral SCCs compared with normal gingivae. TPX2 mRNA was significantly higher in stage III/IV oral SCCs than in stage I/II oral SCCs. Patients with tumors that have high expression of TPX 2 mRNA have a lower survival rate than patients with low expression (data not shown). Furthermore, a significant relationship was found between the mRNA expression levels of RHAMM and TPX2. These results indicate a strong correlation between TPX2 and RHAMM in oral SCCs. Our observations suggest that the up-regulation of human RHAMM and TPX2 correlate with the malignant condition. In conclusion, increased expression of RHAMM and TPX2 might play an important role in malignant transformation of the oral epithelium and proliferation of oral SCC.

\section{Acknowledgements}

This study was supported by a Grant-in-Aid from the Japanese Ministry of Education, Culture, Sports and Technology. 


\section{References}

1. Hardwick C, Hoare K, Owens R, Hohn HP, Hook M, Moore D, Cripps V, Austen L, Nance DM and Turley EA: Molecular cloning of a novel hyaluronan receptor that mediates tumor cell motility. J Cell Biol 117: 1343-1350, 1992.

2. Assmann V, Jenkinson D, Marshall JF and Hart IR: The intracellular hyaluronan receptor RHAMM/IHABP interacts with microtubules and actin filaments. J Cell Sci 112: 3943-3954, 1999

3. Maxwell CA, Keats JJ, Crainie M, Sun X, Yen T, Shibuya E, Hendzel M, Chan G and Pilarski LM: RHAMM is a centrosomal protein that interacts with dynein and maintains spindle pole stability. Mol Biol Cell 14: 2262-2276, 2003.

4. Maxwell CA, Keats JJ, Belch AR, Pilarski LM and Reiman T: Receptor for hyaluronan-mediated motility correlates with centrosome abnormalities in multiple myeloma and maintains mitotic integrity. Cancer Res 65: 850-860, 2005.

5. Tulu US, Fagerstrom C, Ferenz NP and Wadsworth P: Molecular requirements for kinetochore-associated microtubule formation in mammalian cells. Curr Biol 16: 536-541, 2006.

6. Tsai MY, Wiese C, Cao K, Martin O, Donovan P, Ruderman J, Prigent $C$ and Zheng Y: A Ran signalling pathway mediated by the mitotic kinase Aurora A in spindle assembly. Nat Cell Biol 5: 242-248, 2003

7. Marumoto T, Zhang D and Saya H: Aurora-A - a guardian of poles. Nat Rev Cancer 5: 42-50, 2005.

8. Fu J, Bian M, Jiang Q and Zhang C: Roles of Aurora kinases in mitosis and tumorigenesis. Mol Cancer Res 5: 1-10, 2007.

9. Zhang S, Chang MC, Zylka D, Turley S, Harrison R and Turley EA: The hyaluronan receptor RHAMM regulates extracellular-regulated kinase. J Biol Chem 273: 11342-11348, 1998.

10. Cheng M, Zhen E, Robinson MJ, Ebert D, Goldsmith E and Cobb MH: Characterization of a protein kinase that phosphorylates serine 189 of the mitogen-activated protein kinase homolog ERK3. J Biol Chem 271: 12057-12062, 1996.

11. Wittmann T, Boleti H, Antony C, Karsenti E and Vernos I: Localization of the kinesin-like protein Xklp2 to spindle poles requires a leucine zipper, a microtubule-associated protein, and dynein. J Cell Biol 143: 673-685, 1998.

12. Crainie M, Belch AR, Mant MJ and Pilarski LM: Overexpression of the receptor for hyaluronan-mediated motility (RHAMM) characterizes the malignant clone in multiple myeloma: identification of three distinct RHAMM variants. Blood 93: 1684-1696, 1999.

13. Wang C, Thor AD, Moore DH II, Zhao Y, Kerschmann R, Stern R, Watson PH and Turley EA: The overexpression of RHAMM, a hyaluronan-binding protein that regulates ras signaling, correlates with overexpression of mitogen-activated protein kinase and is a significant parameter in breast cancer progression. Clin Cancer Res 4: 567-576, 1998.
14. Rein DT, Roehrig K, Schöndorf T, Lazar A and Fleisch M: Expression of the hyaluronan receptor RHAMM in endometrial carcinomas suggests a role in tumour progression and metastasis. J Cancer Res Clin Oncol 129: 161-164, 2003.

15. Yamano Y, Uzawa K, Shinozuka K, Fushimi K, Ishigami T, Nomura H, Ogawara K, Shiiba M, Yokoe H and Tanzawa $\mathrm{H}$ : Hyaluronan-mediated motility: a target in oral squamous cell carcinoma. Int J Oncol 32: 1001-1009, 2008.

16. Lugli A, Zlobec I, Günthert U, Minoo P, Baker K, Tornillo L, Terracciano L and Jass JR: Overexpression of the receptor for hyaluronic acid mediated motility is an independent adverse prognostic factor in colorectal cancer. Mod Pathol 19: 1302-1309, 2006.

17. Maxwell CA, Rasmussen E, Zhan F, Keats JJ, Adamia S, Strachan E, Crainie M, Walker R, Belch AR, Pilarski LM, Barlogie B, Shaughnessy J Jr and Reiman T: RHAMM expression and isoform balance predict aggressive disease and poor survival in multiple myeloma. Blood 104: 1151-1158, 2004.

18. Wang C, Entwistle J, Hou G, Li Q and Turley EA: The characterization of a human RHAMM cDNA: conservation of the hyaluronan-binding domains. Gene 174: 299-306, 1996.

19. Sobin LH and Wittekind C (eds). TNM Classification of Malignant Tumors. 5th edition. John Wiley \& Sons, New York, 1997.

20. World Health Organization: International Histological Classification of Tumors. 2nd edition. Springer, Berlin, 1998.

21. Kubista M, Andrade JM, Bengtsson M, Forootan A, Jonák J, Lind K, Sindelka R, Sjöback R, Sjögreen B, Strömbom L, Ståhlberg $\mathrm{A}$ and Zoric N: The real-time polymerase chain reaction. Mol Aspects Med 27: 95-125, 2006.

22. Ma Y, Lin D, Sun W, Xiao T, Yuan J, Han N, Guo S, Feng X, Su K, Mao Y, Cheng S and Gao Y: Expression of targeting protein for xklp2 associated with both malignant transformation of respiratory epithelium and progression of squamous cell lung cancer. Clin Cancer Res 12: 1121-1127, 2006.

23. Livak KJ and Schmittgen TD: Analysis of relative gene expression data using real-time quantitative PCR and the 2(-Delta Delta C(T)) method. Methods 25: 402-408, 2001.

24. Turley EA, Bowman P and Kytryk MA: Effects of hyaluronate and hyaluronate binding proteins on cell motile and contact behaviour. J Cell Sci 78: 133-145, 1985.

25. Wittmann T, Wilm M, Karsenti E and Vernos I: TPX2, A novel xenopus MAP involved in spindle pole organization. J Cell Biol 149: $1405-1418,2000$ 